Apartado 3

Propuestas y planes de actuación sobre centros históricos

\title{
accésit
}

\section{VIVIENDAS EN AZOTEAS}




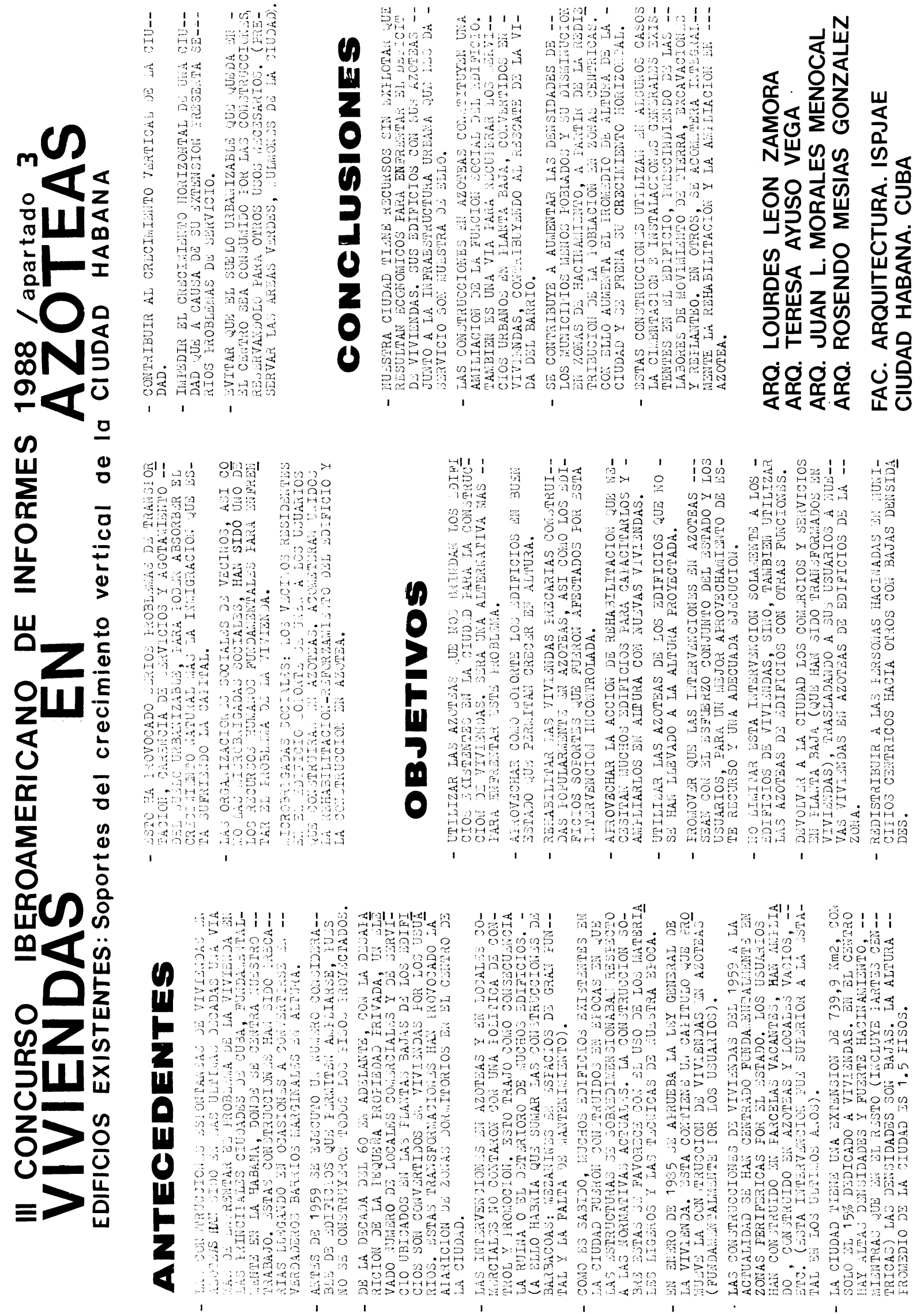



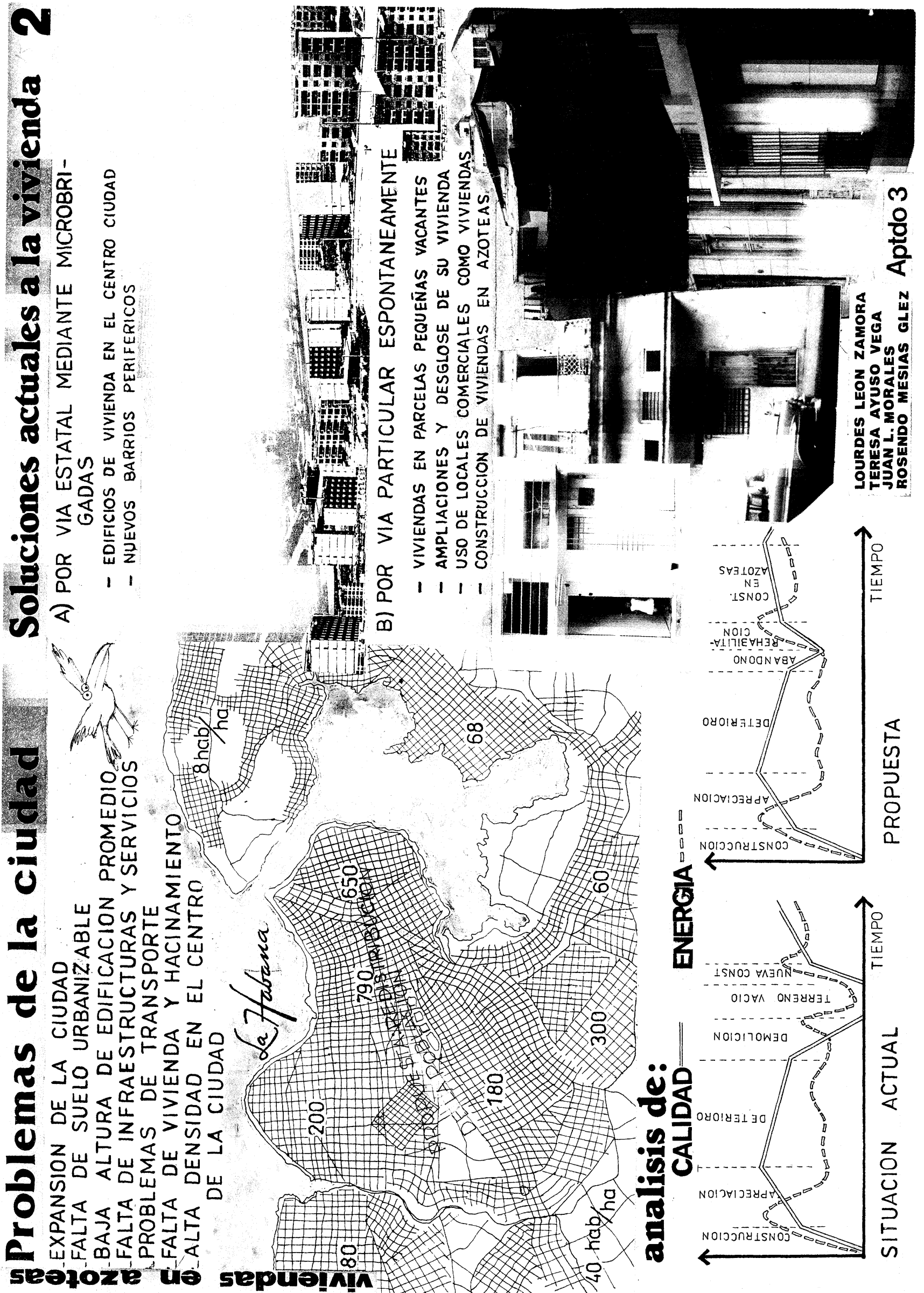

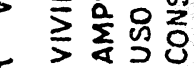

Jon

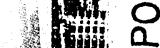

1111
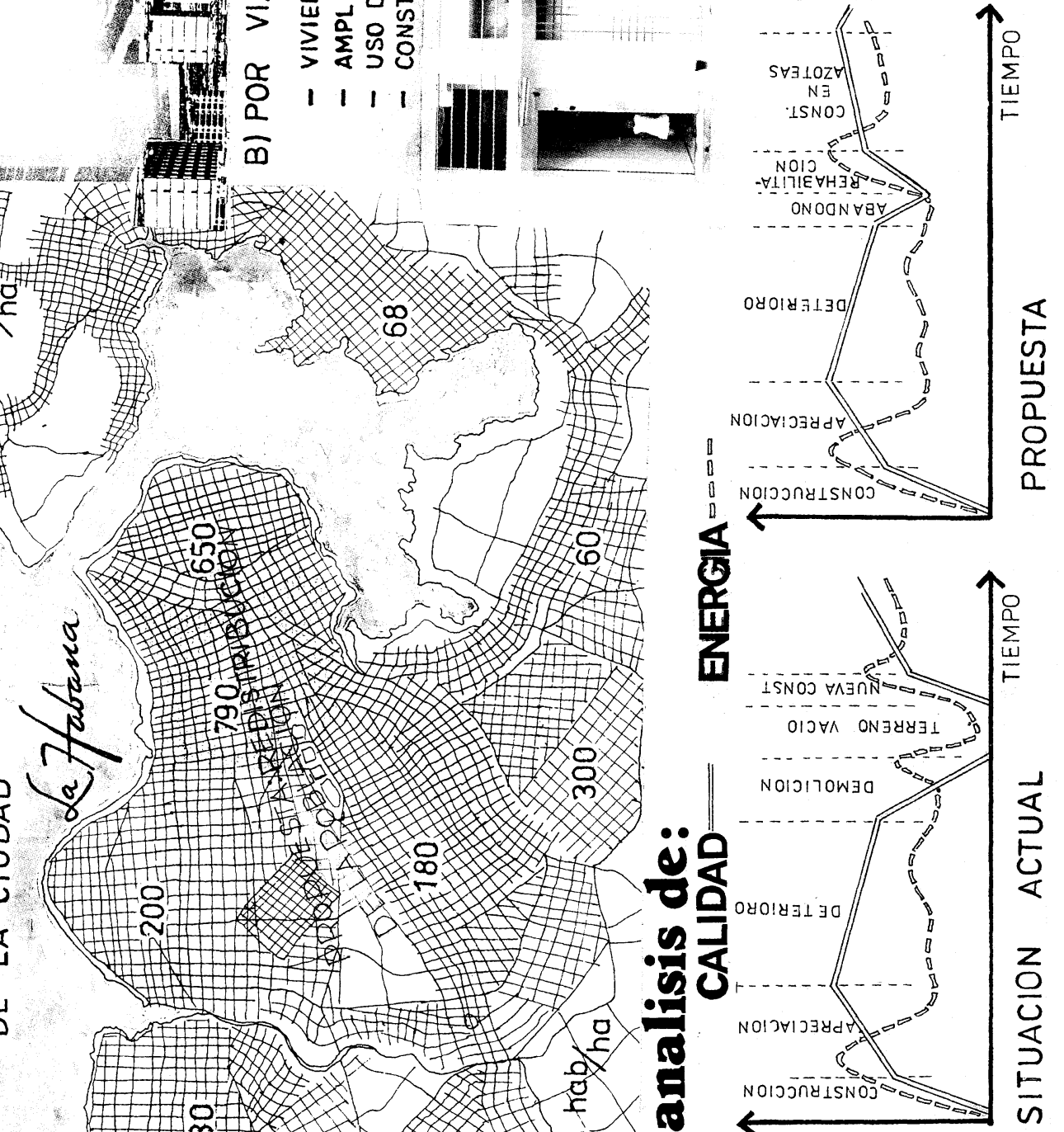


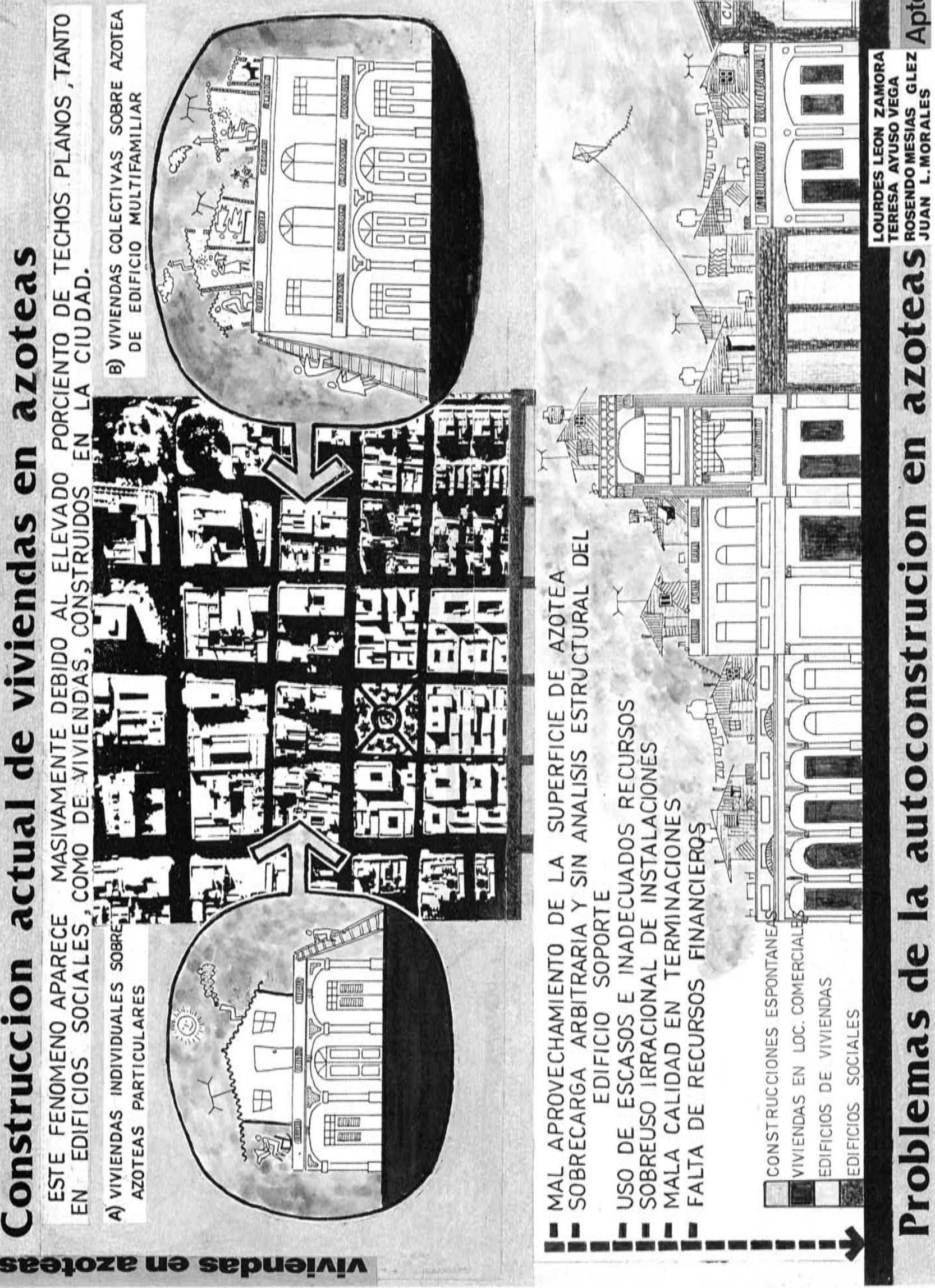




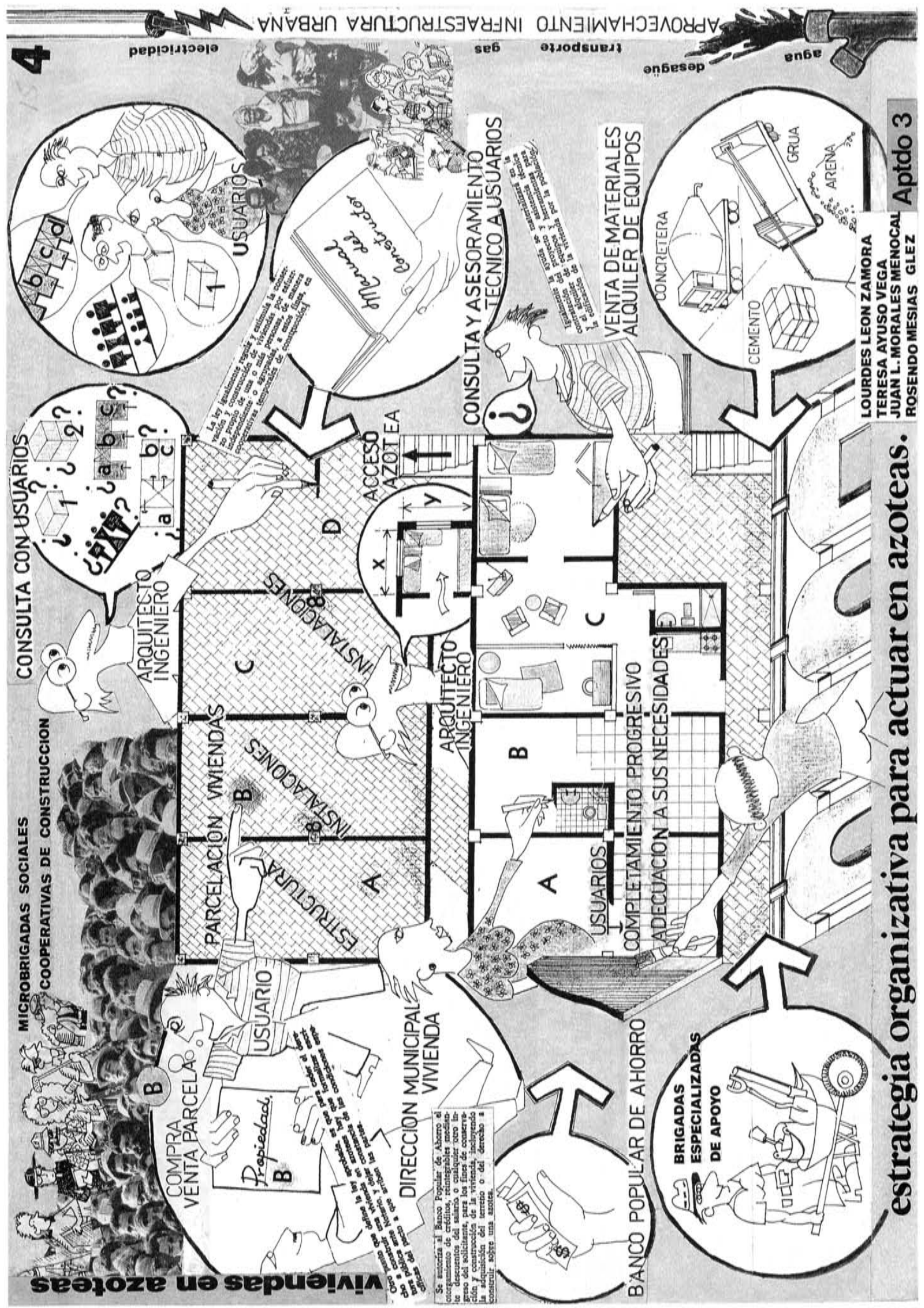




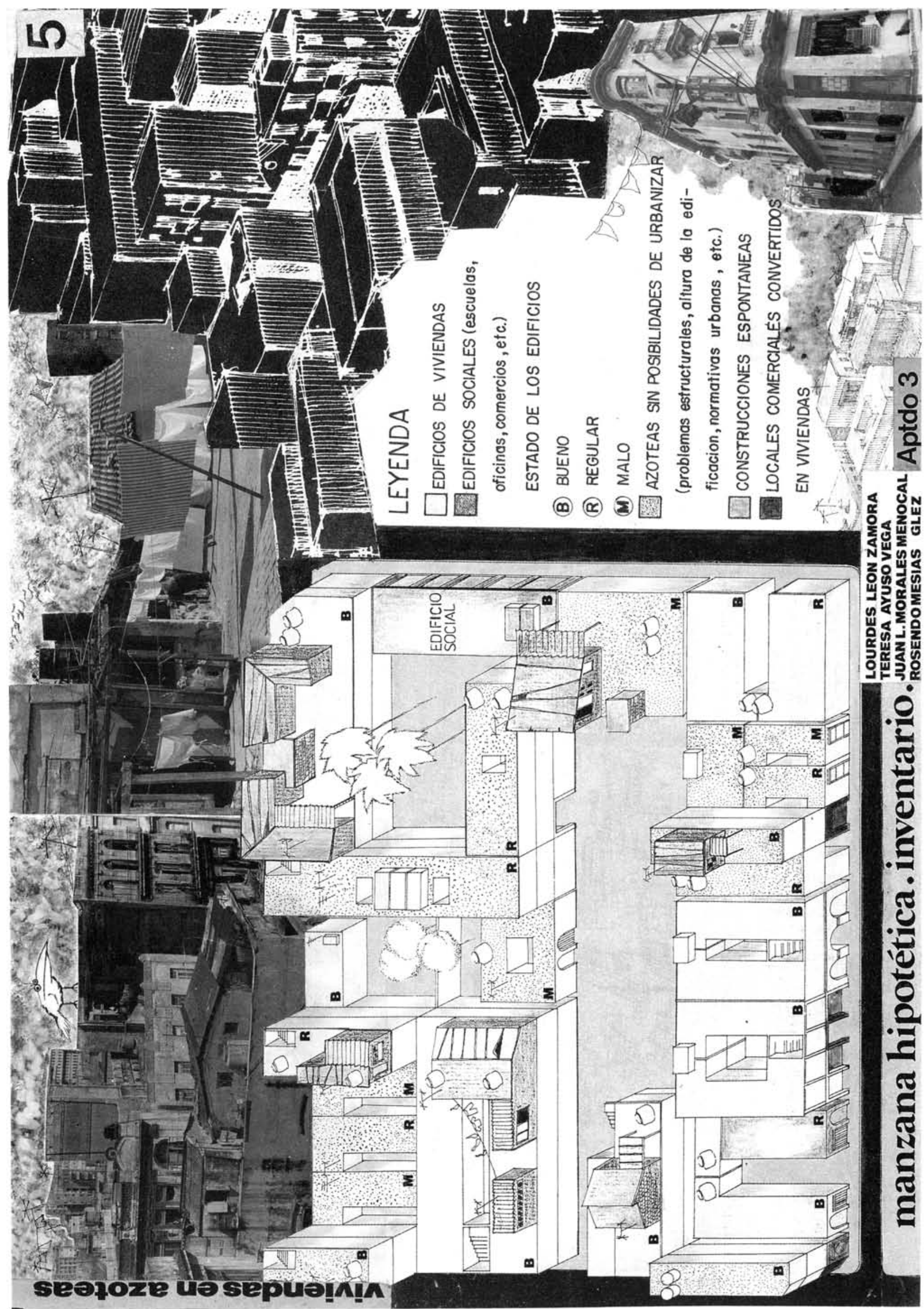




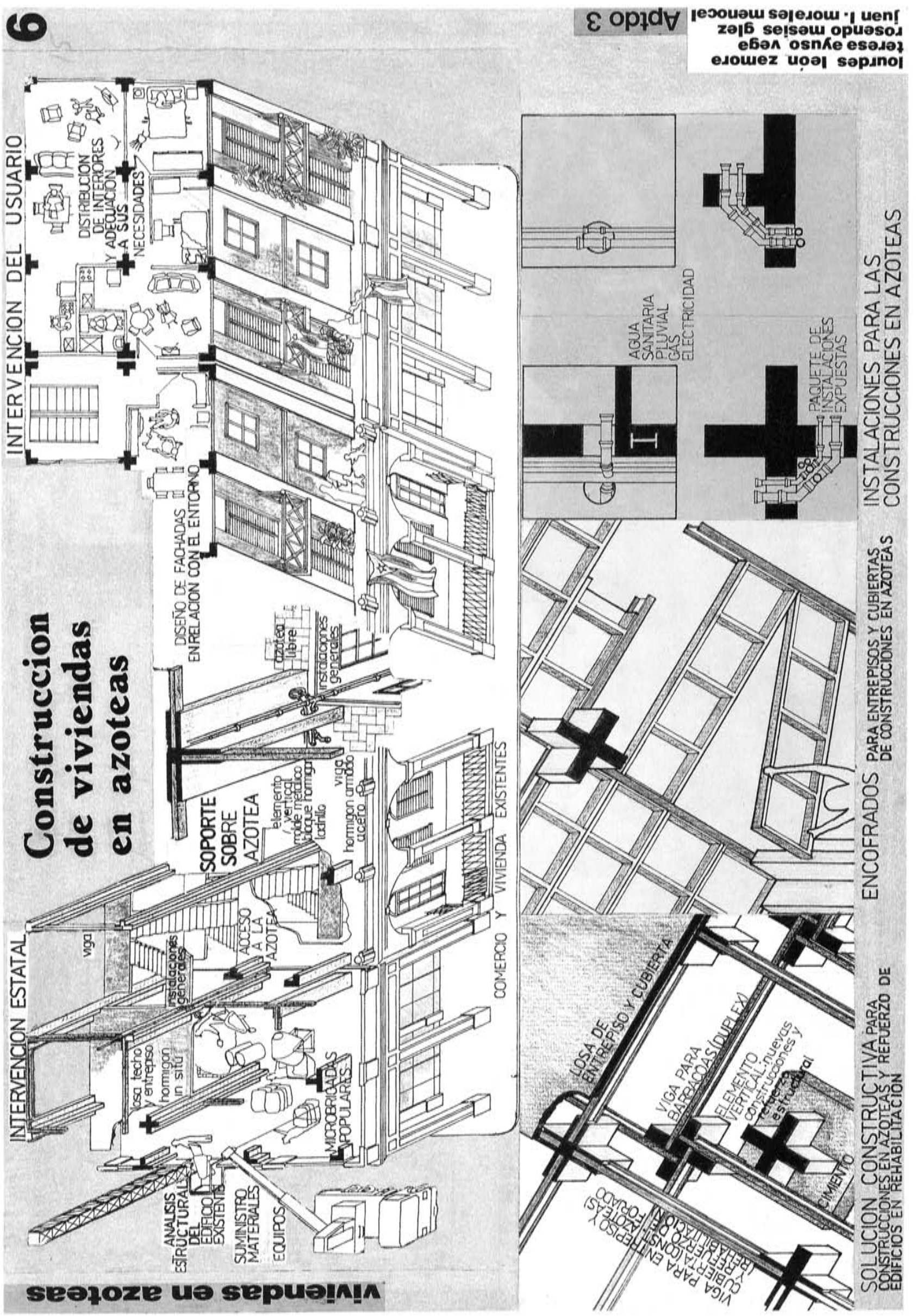




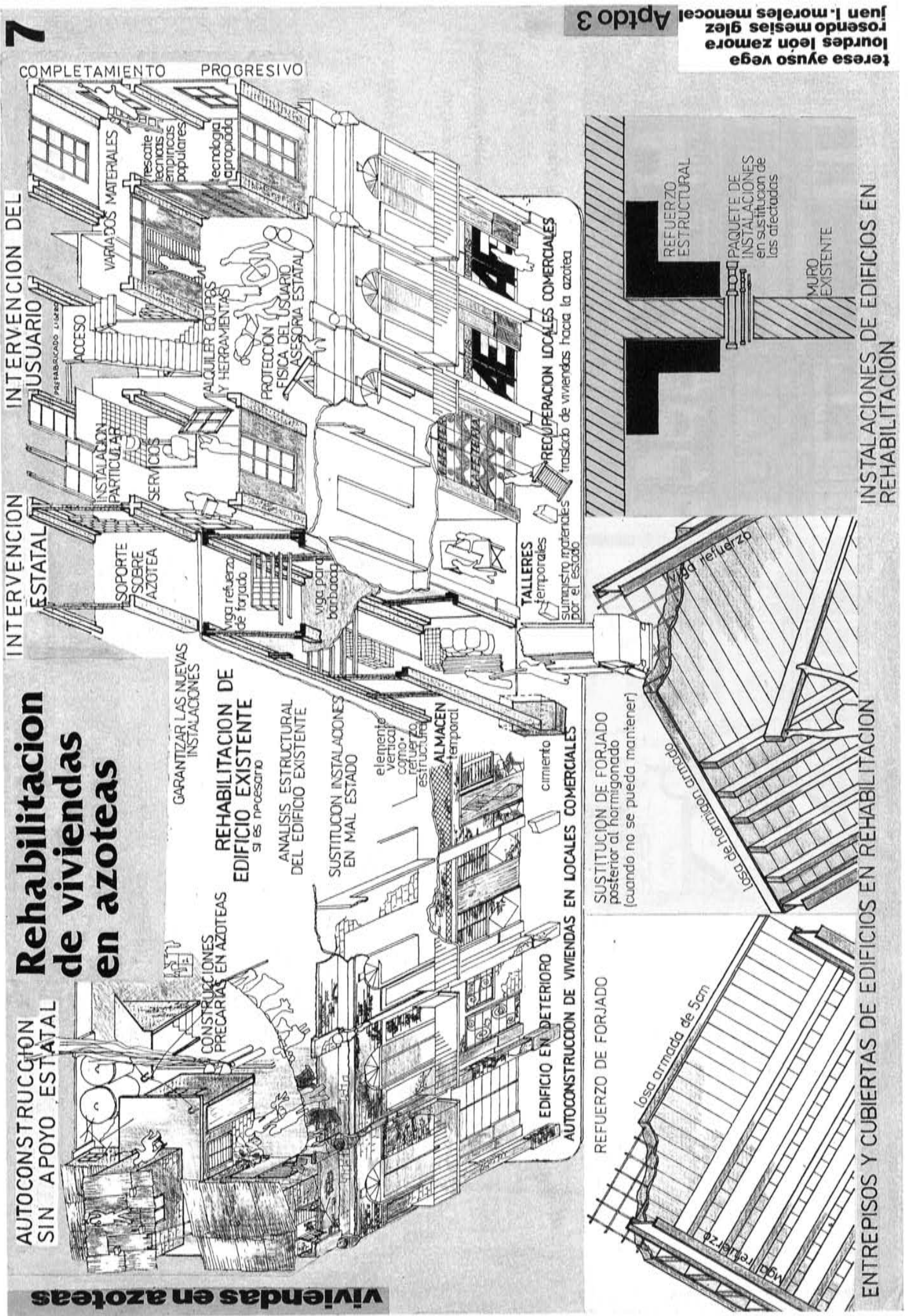




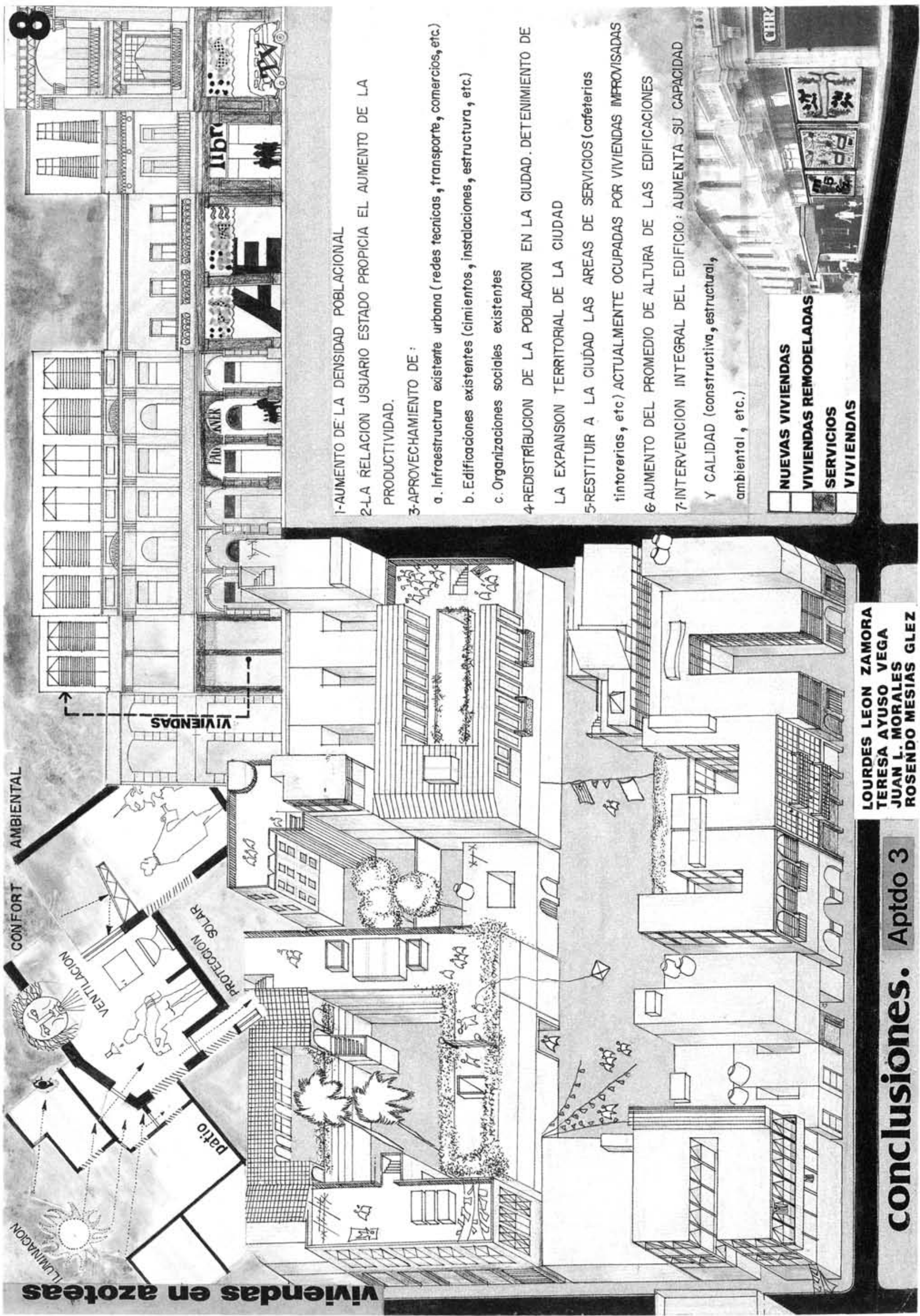

